\title{
EOS Model and Black-Oil PVT Table Generation for a Tanzanian Reservoir
}

\author{
Oras Joseph Mkinga \\ Jon Kleppe \\ Richard Wilfred Rwechungura \\ Department of Geoscience and Petroleum \\ Norwegian University of Science and Technology \\ N-7031 Trondheim, Norway \\ Matheo L. Raphael \\ Department of Chemical and Mining Engineering \\ University of Dar es Salaam \\ P.O. Box 35131 \\ Dar es Salaam, Tanzania
}

\begin{abstract}
Tuning of an EOS model and generation of Black-oil PVT tables for a gas field in Tanzania, here named R reservoir, are presented. The Soave-Redlich-Kwong equation of state was tuned using experimental data and PhazeComp software to obtain the EOS model which represents fluid behavior change in the R reservoir. A contribution is provided in a relationship between specific gravity and molecular weight, which is a modified form of Soreide equation for C7+ characterization. Constants of the equation are determined using linear regression to fit experimental data. A residual oil in the reservoir is recognized using EOS calculation; PVT data generated in this paper can be used to study its potential to condensate blockage and well deliverability. Gas and oil PVT tables are generated for saturated and undersaturated condition, they can be used in reservoir simulation of $R$ reservoir.
\end{abstract}

Keywords: Black-oil PVT table generation; EOS characterization; EOS model; Gamma fitting; Specific gravity.

\section{Introduction}

PVT properties are essential to simulate reservoir fluid flow dynamics (behaviors) during the production and convert produced volumes to reservoir conditions. Fundamental gas properties that control the dynamics of gas phase are gas density $\left(\rho_{g}\right)$, gas compressibility $\left(c_{g}\right)$, compressibility factor $(Z)$, gas formation volume factor $\left(B_{g}\right)$, gas viscosity $\left(\mu_{g}\right)$, and solution oil-gas ratio $\left(R_{v}\right)$. Oil properties that control dynamics of oil phase are density $\left(\rho_{o}\right)$, compressibility $\left(c_{o}\right)$, formation volume factor $\left(B_{o}\right)$, viscosity $\left(\mu_{o}\right)$ and solution gas-oil $(R s)$. Water properties that govern the flow behavior of water phase are density $\left(\rho_{w}\right)$, compressibility $\left(c_{w}\right)$, formation volume factor $\left(B_{w}\right)$, viscosity $\left(\mu_{w}\right)$, and gas solubility (GWR). Black-oil simulators needs PVT tables of $\left\{B_{o}, R_{s}, \mu_{o}\right\}$ for the oil phase and $\left\{B_{g}, R_{v}, \mu_{g}\right\}$ for the gas phase to predict production. From these, other properties can be computed in a simulator using inbuilt relationships.

Black-oil PVT tables can be generated using modeling software which solves an equation of state (EOS). The SoaveRedlich-Kwong (SRK) and Peng-Robinson (PR) EOS are the most commonly used cubic EOS's in petroleum industry among many available EOS's. Applying volume translation, both equations provide the same accuracy for vapor-liquid equilibrium predictions and satisfactory volumetric predictions for phases. The PR EOS provides a slightly better behavior predictions at the critical point and better calculation of liquid densities than SRK EOS (Whitson and Brule, 2000; Adewumi, 2018).

Improved calculations for the PR EOS is obtained by tuning binary interaction parameters (BIP's) among hydrocarbons (C1-C7+) pairs to match PVT experimental data. A recommended approach is to tune C1-C7+ BIP's to match saturation pressure (dewpoint or bubblepoint) (Whitson and Brule, 2000; Sah et al., 2011). Changing the BIP's of C1$\mathrm{C} 7+$ pairs affects $K$-values which are function of pressure of the mixture at a given temperature. The change in saturation pressure affects the amount of liquids, thereby affects densities. The C1-C7+ BIP's for PR EOS are nonzero positive values (0.01-0.30) and can be estimated using correlations (e.g., modified Chueh and Prausnitz (1968)). The C1-C7+ BIP's for SRK EOS are very small $( \pm 0.05-0.1)$ whereby zero values can be used and are recommended (Whitson and Brule, 2000; Soave et al., 2010). The BIP's of non-hydrocarbon and hydrocarbon pairs are nonzero, Whitson and Brule (2000) have recommended and reported BIP's for both SRK and PR EOS. 
In this paper, black-oil PVT tables for the gas field in Tanzania named as R reservoir are generated using an EOS model. The model is developed by tuning Soave-Redlich-Kwong (SRK) EOS using experimental data and PhazeComp software (ZickTechnologies, 2012). The PVT data does not include experimental saturation pressure, and this makes the SRK EOS the choice to fit our purpose.

The laboratory gas and oil analysis reports of the $\mathrm{R}$ reservoir were used to obtain data for the EOS modeling. The laboratory analysis involved chromatography (GC) tests of a separator gas and three atmospheric oil samples. The separator gas sample, DST4G, was collected during a drill stem test number 4 of a well R-Y. The analysis of the DST4G sample was performed on-site and mole amounts of components up to C7 plus were reported (RPS-Energy, 2018), and are reproduced in Table 1. The three atmospheric oil samples, namely, G-sand from the well R-Y, K1-sand, and K3-sand from a well R-Z, were collected from extended well tests, and were analyzed by CoreLab (2007). The mass amounts of components up to $\mathrm{C} 33+$ and $\mathrm{C} 35+$ were reported. Compositions, densities, and molecular weight of the heaviest fraction were reported in 2, 4, and 0 decimal places, respectively. These data are sufficient (the minimum requirement of the input data) for EOS modeling to calculate phase and volumetric properties of the fluid mixture (Whitson et al., 1999).

Table 1-Composition of DST4G sample

\begin{tabular}{c|c|c}
$\begin{array}{c}\text { Component } \\
\text { Name }\end{array}$ & $\begin{array}{c}\text { Amount } \\
(\mathrm{mol} \%)\end{array}$ & $\begin{array}{c}\text { Specific } \\
\text { Gravity }\end{array}$ \\
\hline H2 & 0.00 & - \\
N2 & 0.63 & - \\
CO2 & 0.00 & - \\
H2S & 0.00 & - \\
C1 & 96.18 & - \\
C2 & 3.08 & - \\
C3 & 0.01 & - \\
I-C4 & 0.00 & - \\
N-C4 & 0.00 & - \\
I-C5 & 0.00 & - \\
N-C5 & 0.00 & - \\
C6 & 0.07 & - \\
C7+ & 0.03 & - \\
Total & 100.00 & 0.5738 \\
\hline
\end{tabular}

The comparisons of compositional distributions of the oil samples are represented in Figs. 1 through 3. The K1-sand and K3-sand samples looks biodegraded for C9- than the G-sand sample, and they shows a different distribution in a plot which include isomers (Fig. 1) and that of SCN (Fig. 2). However, a normalized distribution of C17+ (Fig. 3) looks somewhat similar.

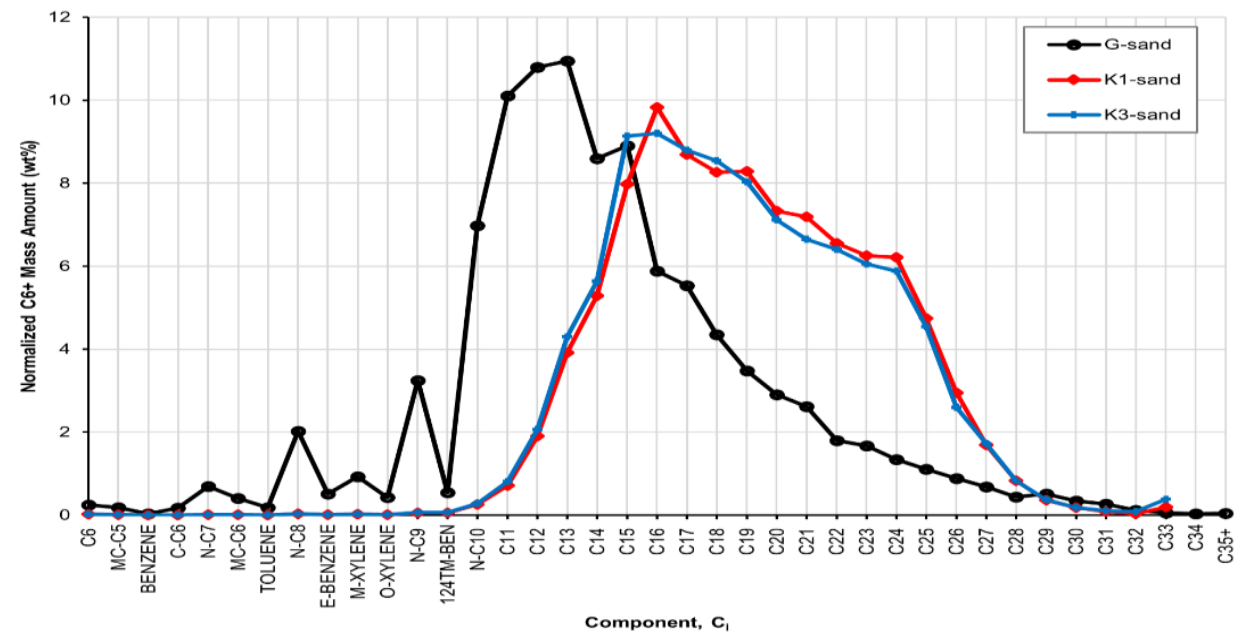

Fig. 1-Comparison of compositions from three oil samples for C6 plus components with isomers 


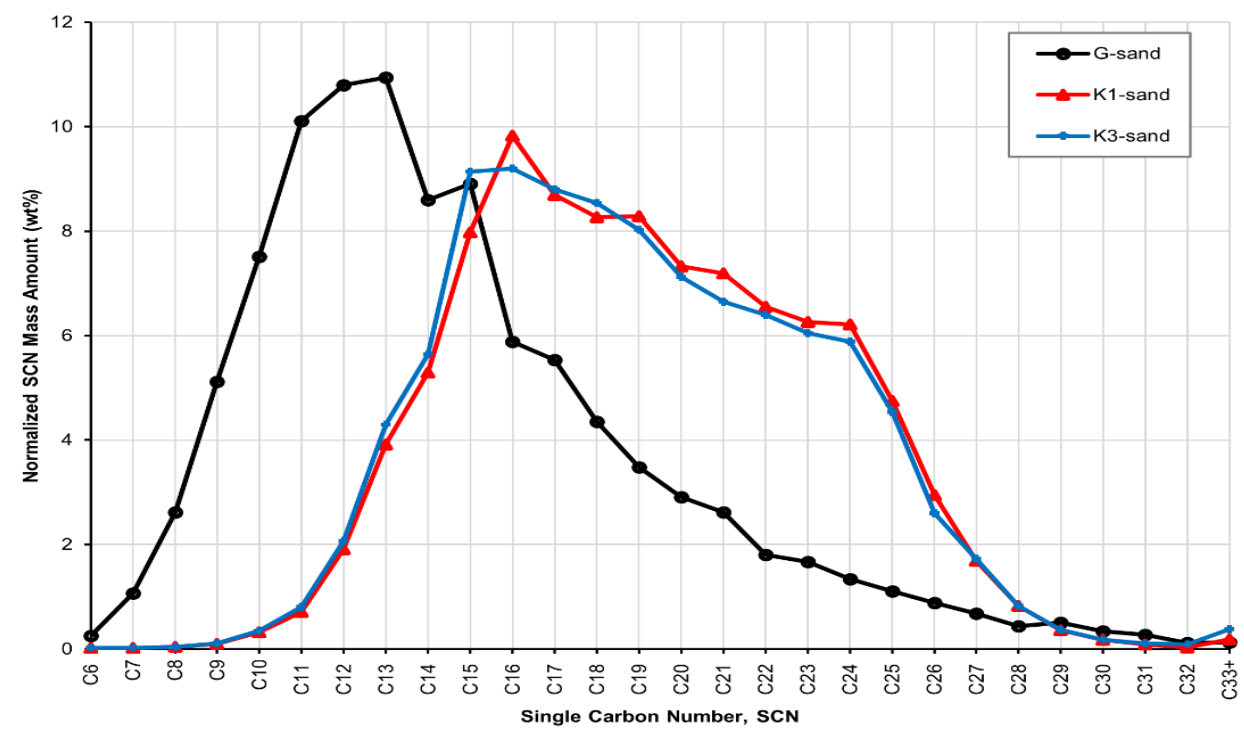

Fig. 2-Comparison of compositions from oil samples for C6 plus SCN

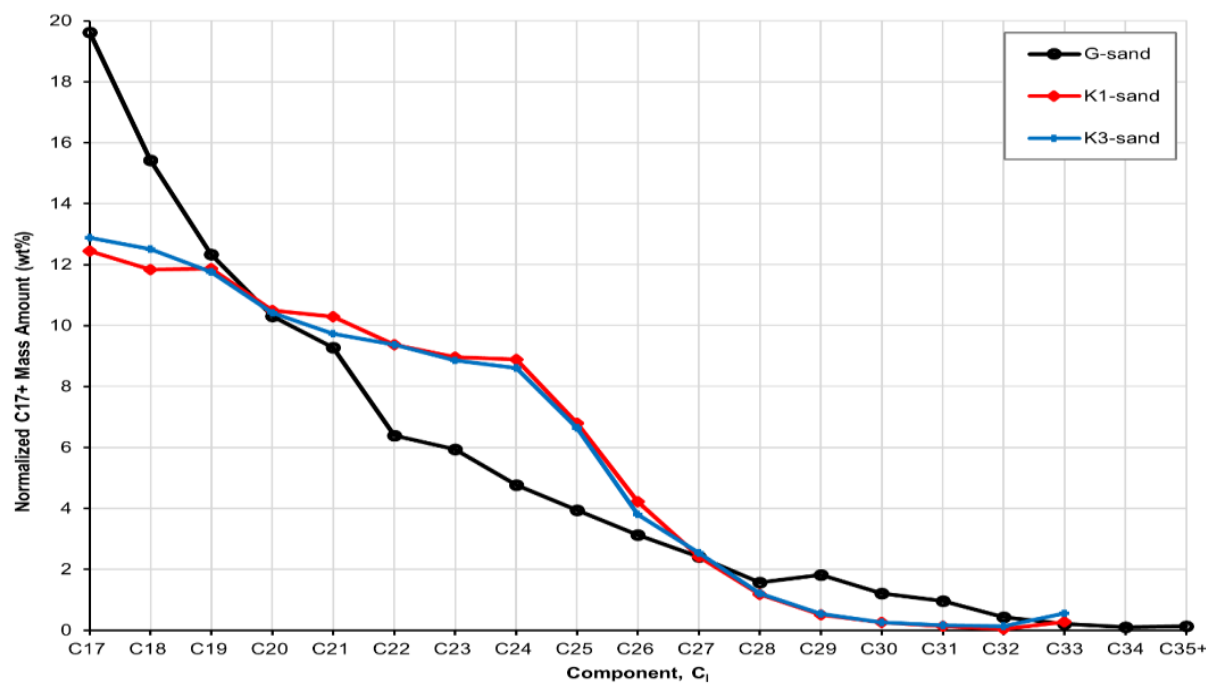

Fig. 3-Comparison of compositions from oil samples for C17 plus SCN

\section{EOS Model Development}

\subsection{Laboratory Characterization}

Components up to $\mathrm{C} 33+$ including isomers were defined with the laboratory reported molecular weights which are Katz and Firoozabadi (1978) for C11 and heavier. The laboratory reported compositions for all samples were assigned in this characterization and mass conservation option was activated for the software to conserve mass because this is the quantity that is measured. The composition of $\mathrm{C} 7$ plus in gas samples was treated as a normal heptane (N-C7) which is a reasonable assumption as it is in small amount $(0.03 \mathrm{~mol} \%$ in Table 1$)$, and zero composition was assigned to heavies. A sample with composition up to $\mathrm{C} 35+$ was averaged to $\mathrm{C} 33+$ to have a single characterization. Single carbon number (SCN) definition was assigned to isomers of $\mathrm{C} 7$ and heavier using "Lump command". This is to simplify characterization to subsequent steps.

\subsection{Specific Gravity and Molecular Weight ( $\gamma$-M) Relationship}

The Soreide (1989) correlation was used to express the relationship between specific gravity $(\gamma)$ and molecular weight $(M)$ as shown in Eq. 1. The characterization factor $\left(C_{f}\right)$, which is a constant in the Eq. 1 was determined in an Excel spreadsheet (outside PhazeComp environment) using the measured $M$ and $\gamma$. The $\gamma$ were estimated using the Eq. 1 with experimental $M$ and an assumed $C_{f}$ of 0.28 . The residual sum of squares (RSS) term was calculated between calculated and experimental $\gamma$. 
Afterward, the RSS term was minimized by adjusting $C_{f}$ value using the Excel Solver to obtain the $C_{f}$ value (0.34) that honor the experimental $\gamma$ and $M$. The comparison between the calculated $\gamma$ and experimental $\gamma$ is shown in Fig. 4, in which a higher deviation is 0.0038 .

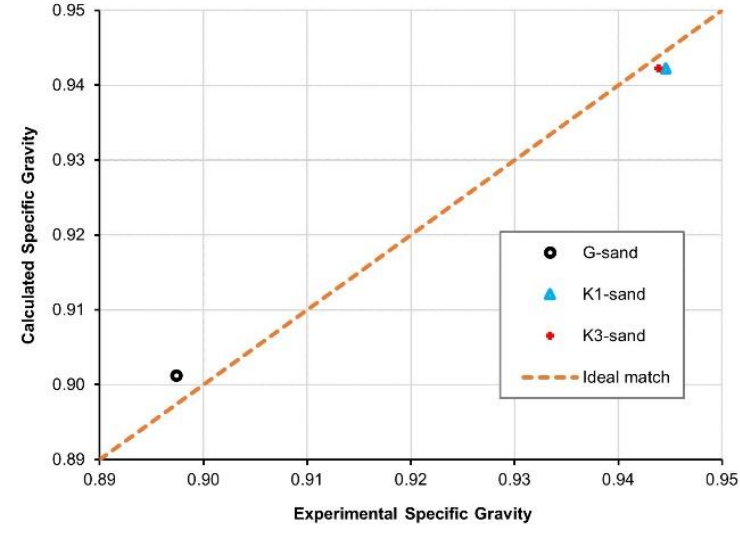

Fig. 4-Comparison of calculated and experimental specific gravity

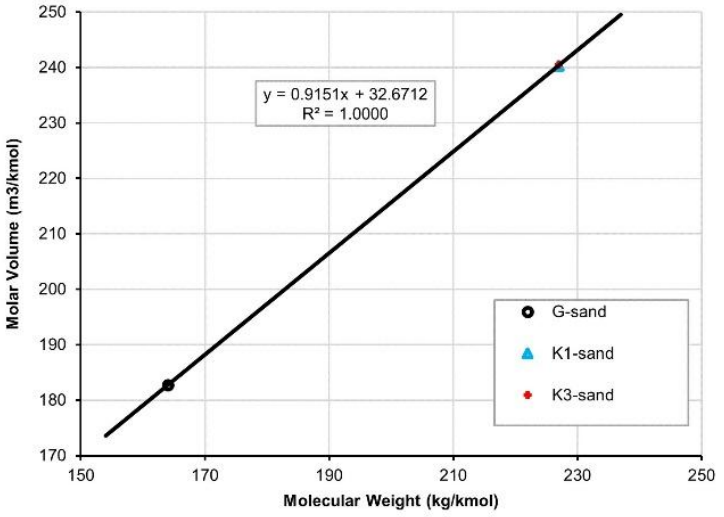

Fig. 5-Molar volume versus molecular weight

$$
\gamma_{i}=0.2855+C_{f}\left(M_{i}-66\right)^{0.13} \text {. }
$$

A linear model (Eq. 2) expressing the relationship between $\gamma$ and $M$ was developed to characterize the three oil samples. Molar volume $(M / \gamma$ ratio) is expressed as a linear function of $M$ (Eq. 2). Where $A$ and $B$ is a slope and intercept respectively of a plot of molar volume against molecular weight using experimental data of the whole sample or heaviest fraction (e.g., $\mathrm{C} 7+$ or $\mathrm{C} 10+)$ as shown in Fig. 5. The $C_{f}$ value of 0.33 fitting the linear model was again established. A comparison of all models is shown in Fig. 6. The linear model can be rearranged to take the form of the Soreide equation as shown in Eq. 3. The Eq. 3 compares to the Eq. 1 such that $C_{f}=M / A$. An application of the equation is tested using 34 fluid samples as shown in Table 2.

Table 2-Comparison of experimental specific gravity with calculation using Soreide and linear equation Experimental

Calculation

\begin{tabular}{c|cc|cc|c|c}
\multicolumn{1}{c}{} & \multicolumn{2}{c}{ Experimental } & \multicolumn{2}{c}{ Calculation } & \multicolumn{2}{c}{ Deviation $(\%)$} \\
\cline { 2 - 6 } Sample & $\mathrm{M}_{7+}$ & $\gamma_{7+}$ & Soreide & Linear & Soreide & Linear \\
\hline Hoffman, et al. & 199 & 0.8409 & 0.8388 & 0.8409 & -0.2486 & 0.0000 \\
Oil & & & & & & \\
Hoffmann, et al. & 141 & 0.7867 & 0.7868 & 0.7867 & 0.0166 & 0.0000 \\
Gas & & & & & & \\
Jacoby, et al. 1 & 143 & 0.7717 & 0.7710 & 0.7717 & -0.0960 & 0.0000 \\
Jacoby, et al. 2 & 193 & 0.7995 & 0.7961 & 0.7995 & -0.4278 & 0.0000 \\
Lee, et al. 1A & 289 & 0.9032 & 0.8853 & 0.9080 & -1.9773 & 0.5268 \\
Lee, et al. 2B & 206 & 0.8498 & 0.8406 & 0.8474 & -1.0814 & -0.2866 \\
Lee, et al. 3C & 348 & 0.9386 & 0.9248 & 0.9361 & -1.4756 & -0.2636 \\
Haaland A & 257 & 0.8725 & 0.8615 & 0.8833 & -1.2600 & 1.2357 \\
Haaland B & 206 & 0.8406 & 0.8330 & 0.8404 & -0.9034 & -0.0282 \\
Haaland C & 258 & 0.8948 & 0.8857 & 0.8840 & -1.0207 & -1.2082 \\
Pedersen BO-1 & 211 & 0.8451 & 0.8374 & 0.8498 & -0.9088 & 0.5591 \\
Pedersen BO-2 & 226 & 0.8528 & 0.8445 & 0.8565 & -0.9700 & 0.4297 \\
Pedersen BO-3 & 254 & 0.8834 & 0.8722 & 0.8670 & -1.2708 & -1.8602 \\
Pedersen BO-4 & 217 & 0.8449 & 0.8365 & 0.8526 & -0.9946 & 0.9088 \\
Pedersen BO-5 & 236 & 0.8525 & 0.8431 & 0.8605 & -1.1024 & 0.9350 \\
Pedersen BO-6 & 265 & 0.8687 & 0.8586 & 0.8705 & -1.1607 & 0.2123 \\
Pedersen BO-7 & 232 & 0.8658 & 0.8569 & 0.8589 & -1.0247 & -0.7963 \\
Pedersen BO-8 & 230 & 0.8650 & 0.8560 & 0.8581 & -1.0372 & -0.7972 \\
Pedersen BO-9 & 231 & 0.8564 & 0.8468 & 0.8585 & -1.1246 & 0.2459 \\
Pedersen BO-10 & 211 & 0.8448 & 0.8374 & 0.8498 & -0.8736 & 0.5948 \\
Pedersen BO-11 & 214 & 0.8458 & 0.8370 & 0.8512 & -1.0433 & 0.6406
\end{tabular}




\begin{tabular}{c|cc|cc|c|c} 
Pedersen BO-12 & 228 & 0.8542 & 0.8454 & 0.8573 & -1.0265 & 0.3618 \\
Albuskjell. No.1 & 171 & 0.8005 & 0.7964 & 0.8007 & -0.5088 & 0.0297 \\
Albuskjell. No.3 & 169 & 0.8008 & 0.7970 & 0.7993 & -0.4773 & -0.1868 \\
Albuskjell. No.4 & 154 & 0.7871 & 0.7848 & 0.7876 & -0.2885 & 0.0591 \\
Albuskjell. No.5 & 177 & 0.8043 & 0.8001 & 0.8049 & -0.5183 & 0.0710 \\
Albuskjell. No.6 & 175 & 0.8033 & 0.7989 & 0.8035 & -0.5457 & 0.0274 \\
Eldfisk No.1 & 220 & 0.8517 & 0.8437 & 0.8544 & -0.9414 & 0.3162 \\
Eldfisk No.2 & 220 & 0.8554 & 0.8475 & 0.8544 & -0.9199 & -0.1177 \\
Eldfisk No.3 & 232 & 0.8601 & 0.8530 & 0.8577 & -0.8208 & -0.2833 \\
Eldfisk No.4 & 256 & 0.8626 & 0.8591 & 0.8633 & -0.4016 & 0.0862 \\
Alaska No.1 & 279 & 0.9039 & 0.8978 & 0.9064 & -0.6710 & 0.2777 \\
Alaska No.2 & 268 & 0.9033 & 0.8936 & 0.9004 & -1.0707 & -0.3176 \\
Alaska No.3 & 164 & 0.8137 & 0.8118 & 0.8141 & -0.2299 & 0.0449 \\
\hline
\end{tabular}

$\left(\frac{M_{i}}{\gamma_{i}}\right)=A M_{i}+B$.

$\gamma_{i}=\frac{M_{i}}{A}\left[M_{i}-\left(-\frac{B}{A}\right)\right]^{-1}$.

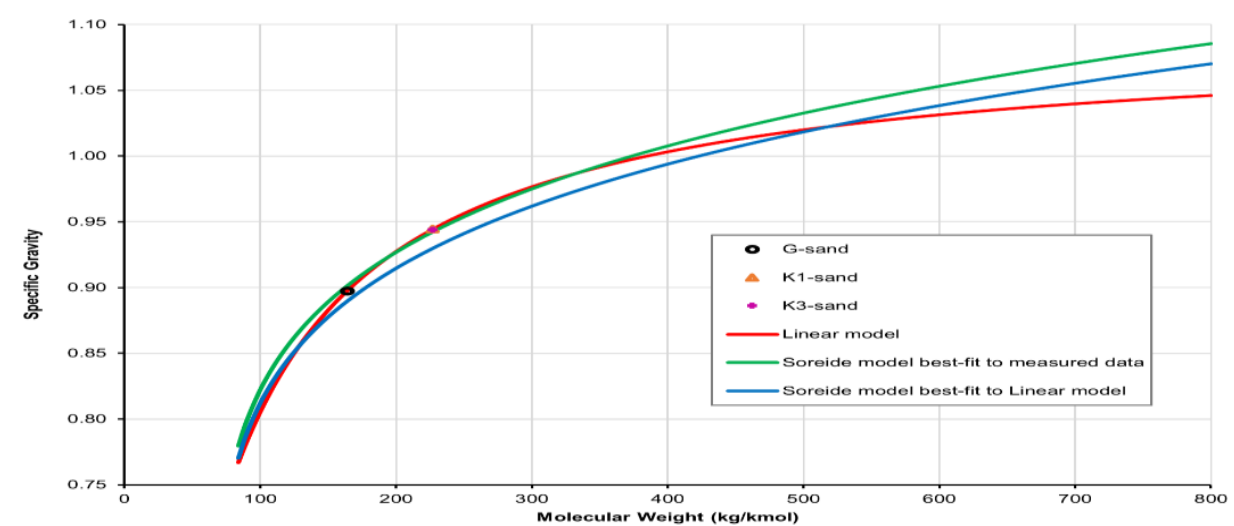

Fig. 6 - Comparison of $\gamma$-M models

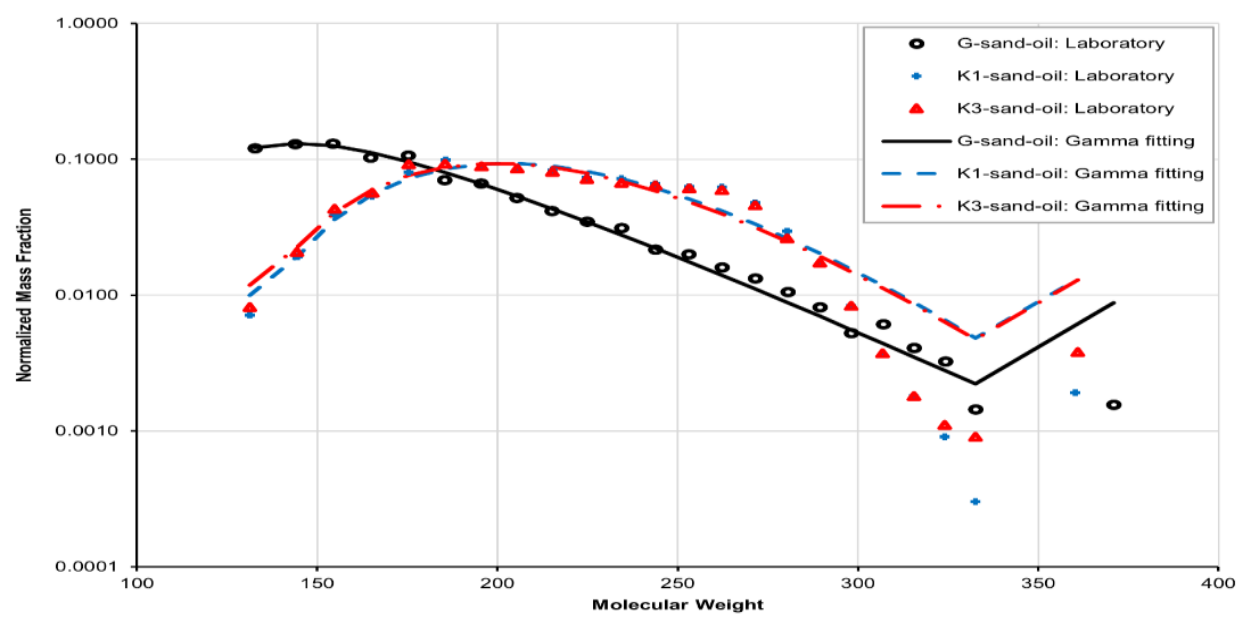

Fig. 7-Gamma fitting of laboratory measured C11+ 


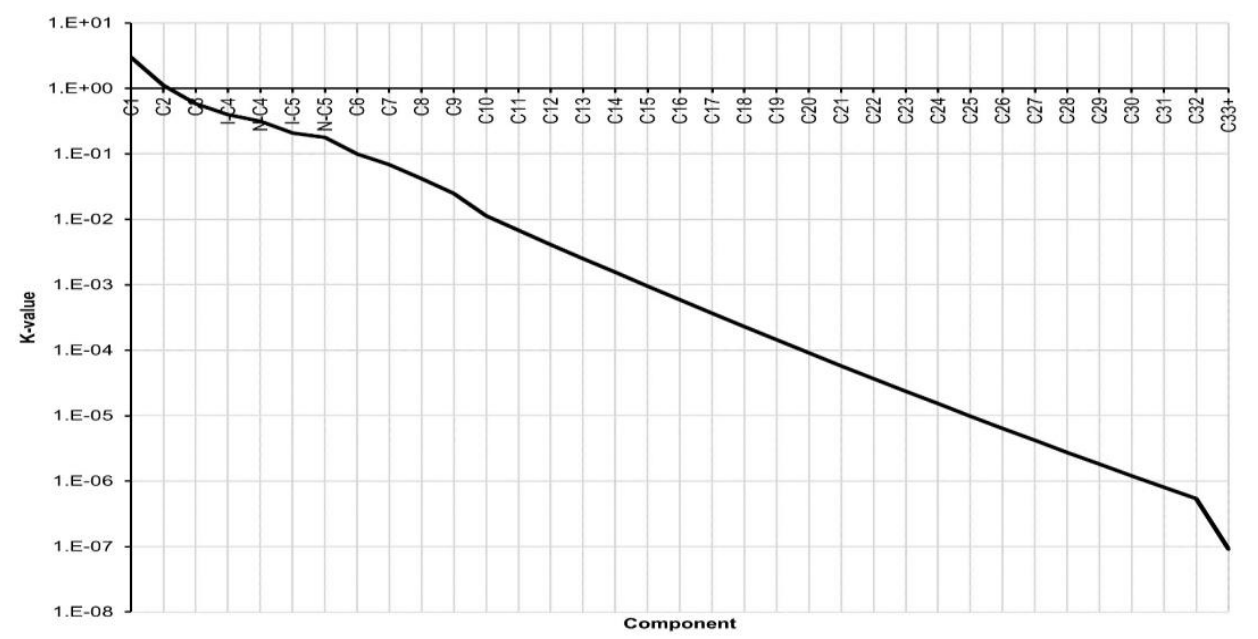

Fig. 8-Equilibrium constants of reservoir mixture at $85.94^{\circ} \mathrm{C}$ and dewpoint pressure

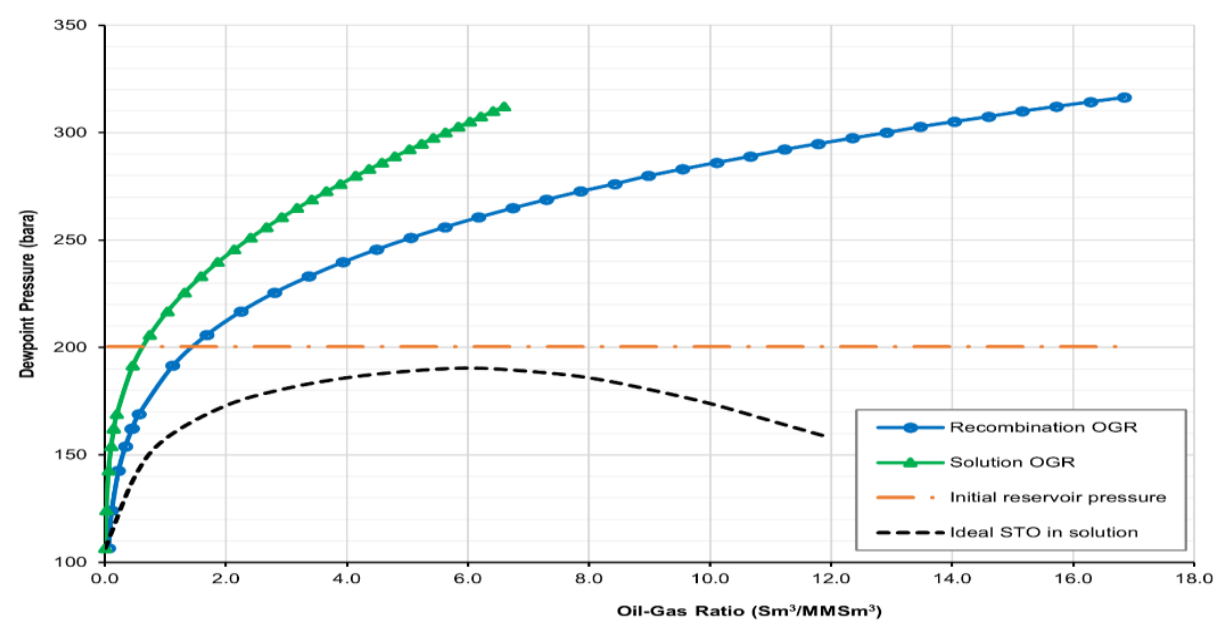

Fig. 9-Dewpoint pressure as a function of recombination oil-gas ratio

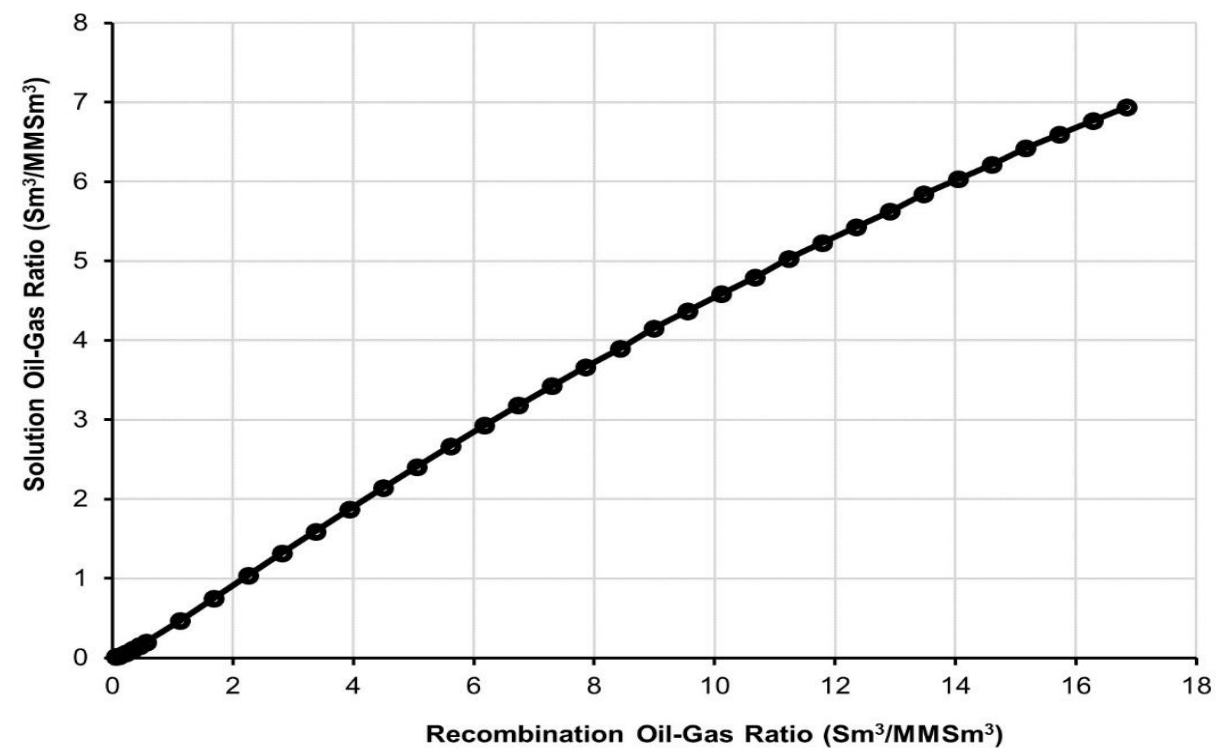

Fig. 10-Solution against recombination oil-gas ratio 


\subsection{Gamma Fitting}

The Soreide parameters best fit to all measured data were used in the gamma fitting (

Fig. 7) of the three atmospheric oil samples. The Twu (1984) correlation was used to link the $M$, $\gamma$, boiling points $\left(T_{b}\right)$, and carbon number. The Twu (1984) correlations can handle the behavior of the aromatic components to have higher $\gamma$ and $M$ than the paraffinic components for a given carbon number (or boiling point range). This behavior is controlled by the term called TwuMW damping factor in the PhazeComp software, which is a number between zero and unity inclusively. The TwuMW damping factor slack off the influence of $\gamma$ on the Twu correlation for the relationship between $M$ and $T_{b}$. The TwuMWof unity means that the Twu correlations are honored, and zero means that the relationship between $M$ and $T_{b}$ is that of normal paraffins. A number between extremes of the range 0-1 means that the $M-T_{b}$ relationship is interpolated between paraffinic and aromatic components.

The gamma fitting was performed for C11+ mass amounts with TwuMW damping factor of a unity. This is to allow $M$ determined by Twu (1984) correlation to honor specific gravities from Soreide equation which is appropriate for these samples as they looks aromatic. The aromaticity of samples was confirmed by determining Watson characterization factor $(K w)$ and Jacoby aromaticity factor $(\mathrm{Ja})$ which are presented in Table 3. An average value of $K w$ obtained was equal to 10.88 which is within a range (8.5 to 11.0) of aromatic compounds presented by Whitson and Brule (2000). The $J a$ value obtained was greater than zero (0.68) which support the aromaticity to the samples.

\section{Table 3-Characterization factors of samples}

\begin{tabular}{c|c|c}
\multicolumn{2}{c}{$\begin{array}{c}\text { Sample } \\
\text { Name }\end{array}$} & \multicolumn{2}{c}{$\begin{array}{c}\text { Watson } \\
\text { Factor }\end{array}$} & $\begin{array}{c}\text { Jacoby } \\
\text { Factor }\end{array}$ \\
\hline G-sand & 10.83 & 0.63 \\
K1-sand & 10.90 & 0.70 \\
K3-sand & 10.90 & 0.70 \\
Average & 10.88 & 0.68 \\
\hline
\end{tabular}

\subsection{EOS Characterization}

SCN was defined in the EOS characterization section based on the gamma fitting characterization. The isomers average $M$ and $\gamma$ of $\mathrm{C} 7, \mathrm{C} 8$, and $\mathrm{C} 9$ respectively from the G-sand were assigned to these $\mathrm{SCN}$. The $M$ of C33+ was taken from Gamma distribution fit of G-sand. This is because of: firstly, insignificant amounts of isomers (at most $0.11 \mathrm{wt} \%$ ) from other samples compared to G-sand as shown in Figs. 1 through 3. Secondly, good gamma fit for G-sand sample ( Fig. 7). Afterward, lump components were defined as C5p, C6p, C7p, C10p, C11p, C12p, and C30p.

\subsection{Laboratory Experiment}

A quality control of the EOS model was done through conducting a differential liberation expansion (DLE) test. The DLE test was defined at $15.56^{\circ} \mathrm{C}\left(60^{\circ} \mathrm{F}\right)$ and 1.0135 bara $(14.7 \mathrm{psia})$ for the three oil samples to calculate liquid densities, API gravities and molecular weight. Deviations of EOS prediction from laboratory experiments is shown in Table 4.

Table 4-Comparison of experimental measurements and EOS calculations

\begin{tabular}{c|ccc|ccc}
\multicolumn{1}{c}{} & \multicolumn{3}{c}{ Oil Density $\left(\mathrm{g} / \mathrm{cm}^{3}\right)$} & \multicolumn{3}{c}{ Oil Molecular Weight } \\
\cline { 2 - 7 } Sample & Experimental & EOS & $\begin{array}{c}\text { Deviation } \\
(\%)\end{array}$ & Experimental & EOS & $\begin{array}{c}\text { Deviation } \\
(\%)\end{array}$ \\
\hline G-sand & 0.8974 & 0.88800 & -1.05 & 164.00 & 159.87 & -2.52 \\
K1-sand & 0.9446 & 0.93185 & -1.35 & 227.00 & 208.48 & -8.16 \\
K3-sand & 0.9439 & 0.93094 & -1.37 & 227.00 & 206.91 & -8.85 \\
\hline
\end{tabular}

\section{Black-Oil PVT Table Generation}

\subsection{Mathematical Recombination and Dewpoint Pressure Calculation}

Composition of a wellstream mixture was determined through a mathematical recombination of the gas composition in Table 1 and atmospheric oil composition from the G-sand sample. Both compositions are from the same zone with depth interval of 1721.5-1742.2 m SSTVD) in the R-Y well. Recombination gas-oil ratio (GOR) of $2239063 \mathrm{Sm}^{3} / \mathrm{Sm}^{3}$ (12.57 MMscf/STB) from extended well testing (RPS-Energy, 2018) was used in Eq. 4 (Whitson and Brule, 2000) to determine the mole fraction of gas $\left(F_{g}\right)$ in the wellstream mixture. The $F g$ obtained is $0.999942 \mathrm{~mol} / \mathrm{mol}$.

$$
F_{g}=\frac{1}{1+\left[133300\left(\frac{Y}{M}\right)_{0} \frac{1}{R_{\Omega}}\right]}
$$


Dewpoint pressure was computed using the EOS model developed with the wellstream composition at $85.94{ }^{\circ} \mathrm{C}$ $\left(186.7^{\circ} \mathrm{F}\right)$. The dewpoint pressure obtained is 162.16 bara (2351.91 psia). Equilibrium constants ( $K$-values) obtained (Fig. 8) are decreasing monotonically with increasing carbon number, thereby ensuring consistency of EOS model developed.

\subsection{Assessment of Atmospheric Oil Whether is a Solution or Residual Oil at Reservoir Condition}

An assessment was conducted to determine whether the atmospheric oil sample(s) is a stock tank oil in solution with gas or is a residual oil at the reservoir condition. The assessment can provide a basis for the choice of black-oil PVT tables for a reservoir simulation. Example, a gas reservoir contains a residual oil may require gas and oil PVT tables (PVTG and PVTO) to simulate flow behavior. A dry gas reservoir (a gas reservoir with a solution oil-gas ratio, $R_{v}$ equal to zero) can be simulated with gas PVT table (PVDG) only.

Saturation pressure and flash calculation were performed to identify a possible source of the atmospheric oil using the EOS model. The calculation was performed by varying amount of oil-gas ratio (OGR) which is an indirect change of recombination GOR used to make the wellstream composition. A range of OGR used was between 0.056 and 16.844 $\mathrm{Sm}^{3} / \mathrm{MMSm}^{3}$ at a reservoir temperature of $85.94^{\circ} \mathrm{C}$. Flash calculations were performed for wellstream mixtures whose dewpoint pressures were greater than a reservoir pressure (200.4 bara). Both, wellstream mixtures whose dewpoint pressures were less than reservoir pressure, and equilibrium vapors from flash calculation were processed using a twostage EOS separator to obtain solution oil-gas ratio. Temperature and pressure of a primary separator was $30^{\circ} \mathrm{C}$ and 31.03 bara, and secondary (stock tank) separator was at $15.56^{\circ} \mathrm{C}$ and 1.0135 bara. The results of the assessment are represented in Figs. 9 and 10.

\subsection{Black-Oil PVT Table Generation}

The EOS model developed and a procedure proposed by Whitson and Torp (1983) was used to generate black-oil PVT tables for reservoir simulation. The procedure recommends conducting a depletion test (e.g., CVD) of a reference fluid. Afterward, the equilibrium reservoir phases are flushed individually through a multistage (two-stage process in this paper) surface separator to get $\left\{B_{o}, R_{s}, \mu_{o}\right\}$ for the oil phase and $\left\{B_{g}, R_{v}, \mu_{g}\right\}$ for the gas phase.

Equilibrium liquid (incipient phase) and vapor at the dewpoint pressure were used as reference oil and gas respectively to generate black-oil parameters. Constant volume depletion (CVD) test was conducted on each of these fluids for pressure range 162.16-13.79 bara. Equilibrium liquids and vapors from the CVD of oil and gas respectively were collected and flushed individually through the two-stage surface separator to obtain saturated black-oil PVT tables. Extrapolation to undersaturated black-oil PVT tables was done by conducting a reverse DLE test using four stages (the approach was described by Singh et al. (2007) and Whitson and Sunjerga (2012)). In each stage, a fixed amount (0.1 mole) of gas (or equilibrium vapor) was mixed with oil (or equilibrium liquid) to make up a unity total mole to increase the saturation pressure. Both, equilibrium liquids and vapors were collected and flushed individually through the surface separator to obtain undersaturated black-oil PVT tables. The black-oil PVT tables obtained are shown in Figs. 11 through 16.

\section{Results and Discussion}

The SRK EOS is tuned using three atmospheric oil samples which are G-sand, K1-sand, and K3-sand. The percentage error of the EOS model prediction from laboratory experiments is between -1.05 and -1.37 for specific gravities, and between -2.52 and -8.85 for molecular weights as shown in Table 4. An average weighted error of these measurements is $5.1 \%$. These deviations are within the acceptable accuracy of measurements, and the model can be used to generate black-oil PVT tables.

The modified form of the Soreide equation (Eq. 3) is suggesting that $C_{f}$ is proportional to $M$. The constants of the equation are determined using linear regression to fit experimental data, while in Soreide equation, nonlinear regression is used. It was not possible to include the equation in the PhazeComp algorithms because we do not have access to modify it. A comparison between calculated and experimental $\gamma$ is shown using the Soreide and linear equations (Table 2) for 34 samples. The linear equation provides small deviation than Soreide equation in most of the samples.

Assessment of either the atmospheric oil is a solution or residual oil in the reservoir (Fig. 9) shows an increasing dewpoint pressure with OGR (positive monotonic relationship). The recombination OGR of at least 1.472 $\mathrm{Sm}^{3} / \mathrm{MMSm}^{3}$ provides dewpoint pressure greater than reservoir pressure. A monotonic relationship of dewpoint pressure and OGR suggest that the atmospheric oil sample is a residual oil in the reservoir. Otherwise, the atmospheric oil, which is in solution with gas at the reservoir condition is expected to have a non-monotonic trend presented by doted curve in Fig. 9. Thus, dew point pressure increasing just below the reservoir pressure at lower OGR, reaching a maximum at a certain OGR, and afterward decreasing with increasing OGR. 
The presence of residual oil suggests that both gas and oil PVT tables may be necessary for production prediction in simulation. Production issues that may arise because of this residual oil and when bottomhole flowing pressure falls below dewpoint are potential "condensate blockage", well deliverability, and variation of condensate gas ratio (CGR). Reservoir or well modeling studies can substantiate these issues and afterward, recommendation may be provided on the need to include an oil PVT table (PVTO) for production prediction. Currently, none of these issues have been observed in the field (after communicating to field operators and engineer).

PVTG and PVTO data were generated for saturated and undersaturated condition (Figs. 11 through 16). The undersaturated properties were extrapolated to a pressure of 413.69 bara which is greater than the reservoir pressure to ensure numerical stability where pressures may exceed the initial reservoir pressure during iteration.

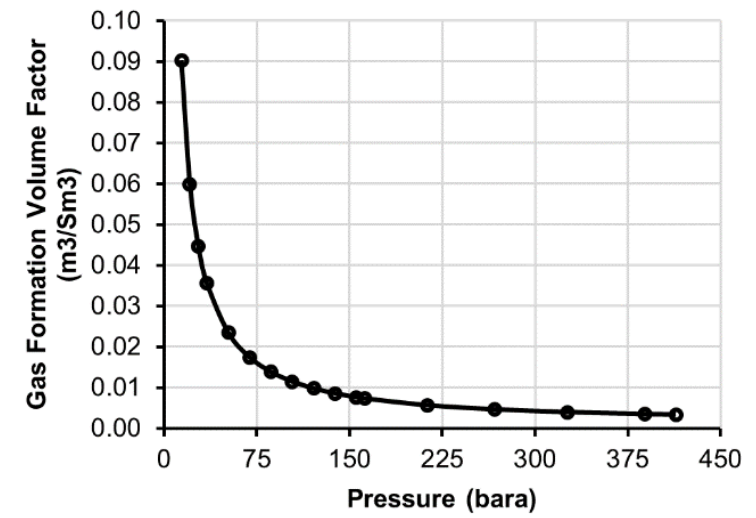

Fig. 11-Gas formation volume factor

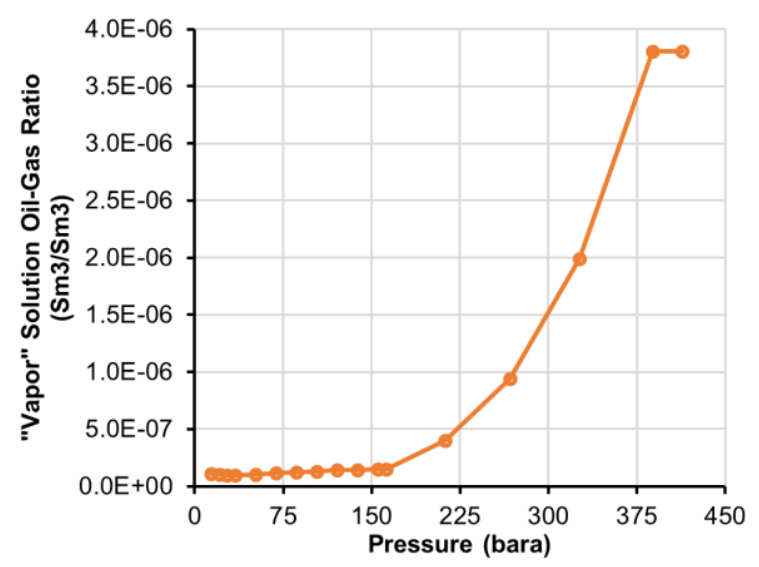

Fig. 12-Solution oil-gas ratio

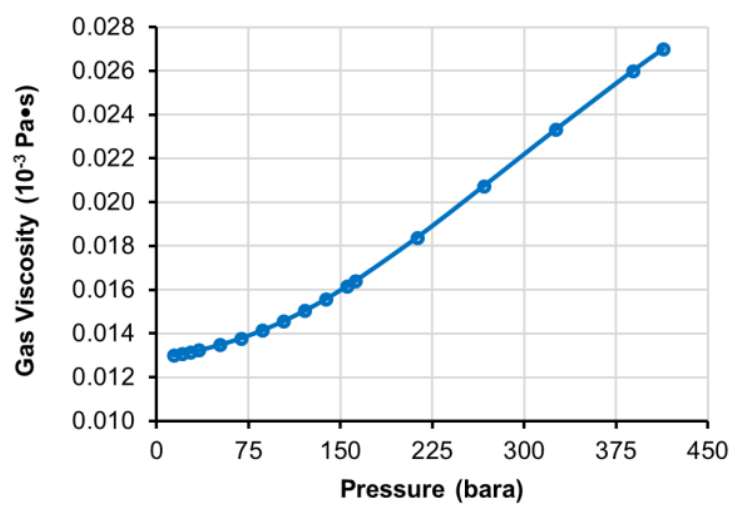

Fig. 13-Gas viscosity

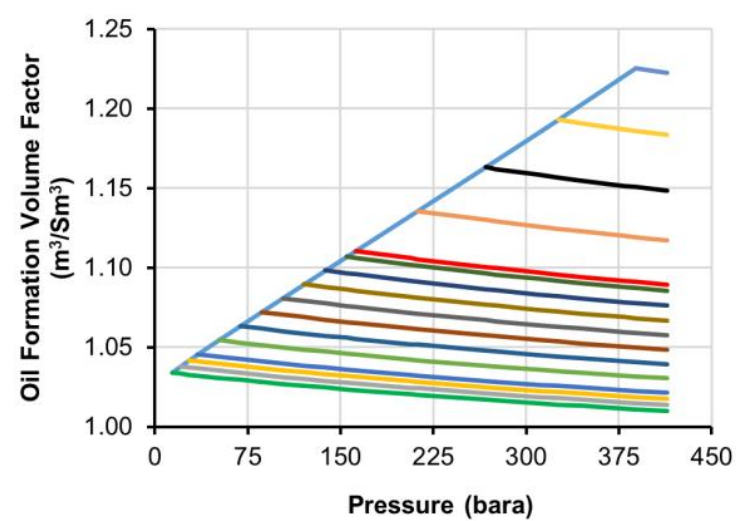

Fig. 14-Oil formation volume factor

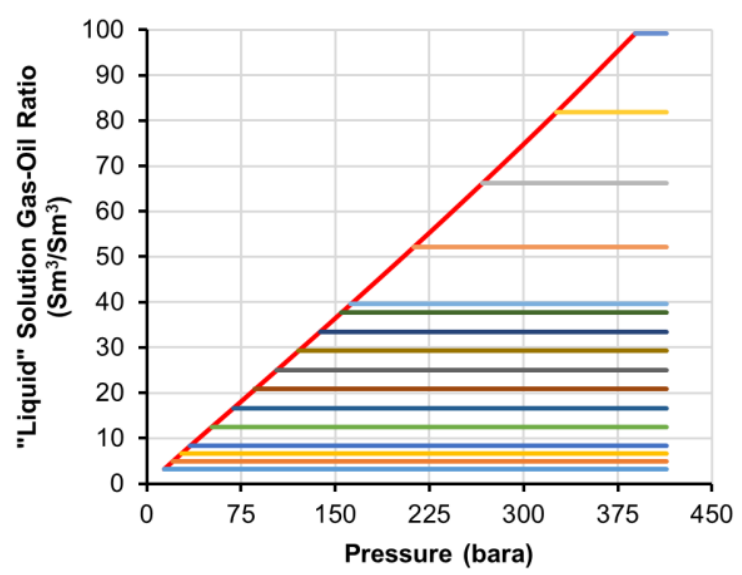

Fig. 15-Solution gas-oil ratio

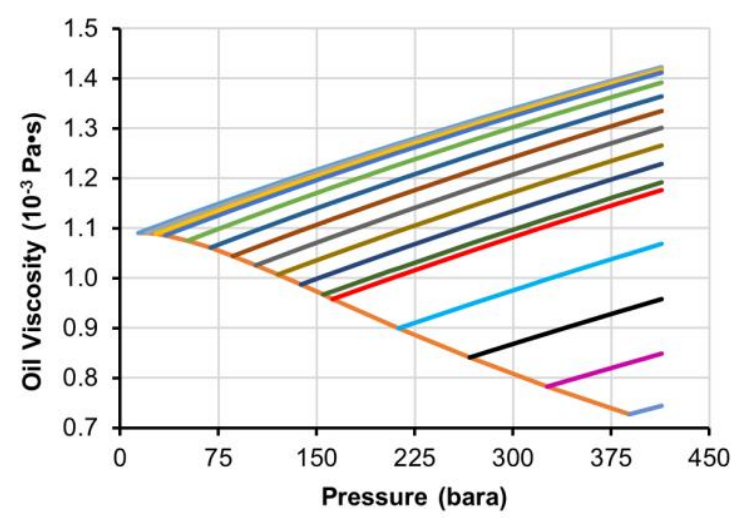

Fig. 16-Oil viscosity 


\section{Conclusions and Future Perspectives}

An EOS model is developed by tuning SRK EOS and can reproduce laboratory measured fluid properties of the R reservoir. A Modified form of Soreide (linear) equation for the relationship between specific gravity and molecular weight is provided and its application is shown for 34 fluid samples. A residual oil in the reservoir is recognized using EOS calculation. Its potential to condensate blockage is not evaluated, but the data generated in this paper can be used for such study. Gas and oil PVT tables are generated for saturated and undersaturated condition, they can be used in reservoir simulation of the $\mathrm{R}$ reservoir.

\section{Acknowledgements}

This project was supported by the Norwegian program for capacity development in higher education and research for development within the fields of energy and petroleum - EnPe 2013-2019 (project no. 25135305). Financial support of the EnPe program is gratefully acknowledged. The authors would also like to acknowledge the Tanzania Petroleum Development Corporation (TPDC) for the permission to use and publish data of the R reservoir in this project.

\section{References}

ADEWUMI, M. 2018. Phase relations in reservoir engineering - Cubic EOS and Their Behavior (III) [Online]. Available: https://www.e-education.psu.edu/png520/m11.html [Accessed 28 November 2018].

CHUEH, P. L. \& PRAUSNITZ, J. 1968. Calculation of High-Pressure Vapor-Liquid Equilibria. Industrial \& Engineering Chemistry, 60, 34-52.http://dx.doi.org/10.1021/ie50699a007.

CORELAB 2007. Compositional Analysis Study. TPDC Internal Report. Dar es Salaam: Tanzania Petroleum Development Corporation (TPDC).

KATZ, D. L. \& FIROOZABADI, A. 1978. Predicting Phase Behavior of Condensate/Crude-Oil Systems Using Methane Interaction Coefficients. Journal of Petroleum Technology, 30, 1649-1655. http://dx.doi.org/10.2118/6721-PA.

RPS-ENERGY 2018. Field Reserves Assessment. Internal Report. Dar es Salaam: Tanzania Petroleum Development Corporation (TPDC).

SAH, P., PEDERSEN, K. S. \& AZEEM, J. 2011. EOS Modeling, The First Step in Detailed EOR Potential Evaluation - A Case Study. SPE Enhanced Oil Recovery Conference. Kuala Lumpur, Malaysia: Society of Petroleum Engineers.https://doi.org/10.2118/144025-MS.

SINGH, K., FEVANG, O. \& WHITSON, C. H. 2007. Consistent Black-Oil PVT Table Modification. SPE Annual Technical Conference and Exhibition. Anaheim, California, U.S.A.: Society of Petroleum Engineers. https://doi.org/10.2118/109596-MS.

SOAVE, G., GAMBA, S. \& PELLEGRINI, L. A. 2010. SRK equation of state: Predicting binary interaction parameters of hydrocarbons and related compounds. Fluid Phase Equilibria, 299, 285-293. https://doi.org/10.1016/j.fluid.2010.09.012.

SOREIDE, I. 1989. Improved Phase Behavior Predictions of Petroleum Reservoir Fluids From a Cubic Equation of State. Doctoral Engineer Reservoir Technique Dissertation, The Norwegian Institute of Technology.

TWU, C. H. 1984. An internally consistent correlation for predicting the critical properties and molecular weights of petroleum and coal-tar liquids. Fluid Phase Equilibria, 16, 137-150.https://doi.org/10.1016/03783812(84)85027-X.

WHITSON, C. H. \& BRULE, M. R. 2000. Phase Behavior, Society of Petroleum Engineers.

WHITSON, C. H., FEVANG, Ø. \& YANG, T. Gas Condensate PVT: What's Really Important and Why? IBC Conference on Optimization of Gas Condensate Fields, London, January 28-29 1999 London, UK.

WHITSON, C. H. \& SUNJERGA, S. 2012. PVT in Liquid-Rich Shale Reservoirs. SPE Annual Technical Conference and Exhibition. San Antonio, Texas, USA: Society of Petroleum Engineers.http://dx.doi.org/10.2118/155499MS.

WHITSON, C. H. \& TORP, S. B. 1983. Evaluating Constant-Volume Depletion Data. Journal of Petroleum Technology, 35, 610-620.http://dx.doi.org/10.2118/10067-PA.

ZICK TECHNOLOGIES. 2012. PhazeComp [Online]. Available: http://www.zicktech.com/phazecomp.html [Accessed 28 November 2018]. 